\title{
Factors associated with motoric cognitive risk syndrome among low-income older adults in Malaysia
}

\author{
Huijin Lau' ${ }^{1}$, Mat Ludin Arimi Fitri ${ }^{1,4^{*}}$, Suzana Shahar ${ }^{1}$, Manal Badrasawi ${ }^{2}$ and Brian C. Clark
}

\begin{abstract}
Background: Motoric cognitive risk (MCR) syndrome is characterized by slow gait and memory complaints that could be used to predict an increased risk of dementia. This study aims to determine the MCR syndrome and its risk factors among low-income (B40) older adults in Malaysia.

Methods: Data from TUA cohort study involving 1366 older adults (aged 60 years and above) categorized as lowincome were analysed, for risk of MCR syndrome based on defined criteria. Chi-square analysis and independent $t$ test were employed to examine differences in socioeconomic, demographic, chronic diseases and lifestyle factors between MCR and non-MCR groups. Risk factors of MCR syndrome were determined using hierarchical logistic regression.
\end{abstract}

Results: A total of $3.4 \%$ of participants fulfilled the criteria of MCR syndrome. Majority of them were female $(74.5 \%, p=0.001)$, single/widow/widower/divorced (55.3\%, $p=0.002)$, living in rural area $(72.3 \%, p=0.011)$, older age (72.74 \pm 7.08 year old, $p<0.001)$ and had lower years of education ( $3.26 \pm 2.91$ years, $p=0.001)$ than non-MCR group. After adjustment for age, gender and years of education, participants living in rural area (Adjusted $\mathrm{OR}=2.19,95 \% \mathrm{Cl}=1.10-4.35, p=0.026$ ), with obesity (Adjusted $\mathrm{OR}=3.82,95 \% \mathrm{Cl}=1.70-8.57$, $p=0.001$ ), diabetes (Adjusted $\mathrm{OR}=2.04,95 \% \mathrm{Cl}=1.01-4.11, p=0.046$ ), heart disease (Adjusted $\mathrm{OR}=2.50$, $95 \% \mathrm{Cl}=1.00-6.20, p=0.049$ ) and cancer (Adjusted $\mathrm{OR}=6.57,95 \% \mathrm{Cl}=1.18-36.65, p=0.032$ ) were associated with increased risk of MCR syndrome.

Conclusion: Only 3.4\% of older adults from low-income group were identified as having MCR syndrome. Women, those living in rural areas, had obesity, diabetes, heart disease and cancer were more likely to have MCR syndrome. Further investigation on MCR as a predementia syndrome will help in development of preventive strategies and interventions to reduce the growing burden of dementia, especially among individuals with low socioeconomic status.

Keywords: Motoric cognitive risk, Low income group, Rural, Obesity, Chronic disease

\section{Background}

Malaysia is fast becoming an aging nation and is expected to reach this status by year 2035 [1]. Aging is accompanied by gradual loss of health and physical strength, especially in the aspects of health and

\footnotetext{
* Correspondence: arimifitri@ukm.edu.my; arimifitri.fsk.ukm@gmail.com ${ }^{1}$ Centre for Healthy Aging and Wellness, Faculty of Health Sciences, Universiti Kebangsaan Malaysia, Jalan Raja Muda Abdul Aziz, 50300 Kuala Lumpur, Malaysia

${ }^{4}$ Program of Biomedical Science, Faculty of Health Sciences, UKM KL Jalan Raja Muda Abd Aziz, Kuala Lumpur 50300, Malaysia

Full list of author information is available at the end of the article
}

physical strength to the elderly [2]. Other than age, studies showed that health determinants among the elderly include adequate exercise, regular medical check-ups, and the absence of health problems [3]. Older adults' attitudes towards aging may also affect their physical performance [4]. The prevalence of dementia is expected to rise 3 to 4 times higher in Malaysia as compared to developed countries [1]. Therefore, as a developing country, Malaysia is facing challenges to minimize the healthcare burden and to sustain the medical expenses of the growing number

(C) The Author(s). 2019 Open Access This article is distributed under the terms of the Creative Commons Attribution 4.0 International License (http://creativecommons.org/licenses/by/4.0/), which permits unrestricted use, distribution, and 
of older population. Abu Bakar et al. [5] found that elderly women were more marginalized and at a disadvantage in socioeconomic aspects of their lives. Therefore, it is essential to increase the accessibility of simple and cost effective dementia risk assessments in order to curtail health care costs.

Gait speed has been accepted as a simple, reliable and valid functional measurement of motor control, strength and gait pattern [6]. Studies suggest that coexistence of cognitive complaints with reduced gait speed may indicate an increased risk of dementia [7-10]. Motoric cognitive risk (MCR) syndrome is a newly defined pre-dementia syndrome characterized by slow gait speed with preserved physical functioning and cognitive complaints without dementia [11]. It can be detected without complex cognitive assessments and is accessible in various clinical settings [12].

A multi-country study reported that the pooled prevalence of MCR syndrome among older adults aged 60 and above was 9.7\% [12]. A recent large-scale population study in Japan established the modifiable risk factors associated with MCR [13]. The findings reported that risk factors such as diabetes, depressive symptoms, falls and obesity were associated with increased risk of MCR syndrome.

As yet little is known about the occurrence of MCR syndrome and its risk factors among low-income populations. In Malaysia, the low income or B40 group is the bottom $40 \%$ of households with an income of less than RM3, 900 per month. The median and mean household income for this group is RM3, 000 per month and RM2, 848 per month, respectively [14]. The present study aims to determine the prevalence of MCR syndrome and its risk factors among low-income (B40) community dwelling older adults in Malaysia.

\section{Methods}

\section{Study design and participants}

The participants eligible for this study were selected from baseline data of a population-based study focusing on neuroprotective model for healthy longevity (TUA) [15]. The TUA study is described elsewhere (cite reference). This study was conducted in four states of Malaysia (Selangor, Perak, Kelantan and Johor) from November 2014 till September 2015. A total of 1366 multiethnic (Malay, Chinese, Indian) participants were identified as low income (i.e., household income of less than RM 3900 per month) together with other inclusion criteria including: 1) community dwelling older adults aged 60 and above, 2) no psychiatric and mental disorders, included dementia 3) no terminal illnesses and 4) preserved functional ability.

\section{MCR criteria}

MCR syndrome was first proposed by Verghese et al. [11] which is a high-risk clinical syndrome with strong predictive validity for dementia that builds on mild cognitive impairment (MCI) operational definitions [16]. The objective cognitive impairment criterion in MCI is substituted with slow gait in MCR syndrome. Cognitive tests are not needed in diagnosing MCR syndrome. Participants were defined as having MCR syndrome if they meet the criteria as outlined in Table 1.

Subjects were defined as not having dementia if they scored less than 14 in Mini Mental State Examination (MMSE). A single dichotomous question "Do you feel you have more problems with memory than most?" on Geriatric Depression Scale (GDS) was administered by trained enumerators to elicit the presence of subjective memory complaints. Participants who answered "yes" on this question were defined as having subjective memory complaints. The same question was used to define subjective cognitive complaints in Doi et al.'s [13] study, as well as other cohorts included in the worldwide MCR prevalence study [16]. Preserved activities of daily living including eating/feeding, dressing, bathing and showering, functional mobility, climbing up and down stairs, personal hygiene and grooming, and toilet hygiene, were determined using ADL questionnaire [17]. Gait speed was measured using a $6 \mathrm{~m}$-distance walk on a level floor over time. Participants were instructed to walk back and forth over the marked distance at their usual pace. Slow gait was defined as 1 SD below mean population gait speed [11].

\section{Potential risk and confounding factors}

Potential sociodemography risk factors comprising age, gender, educational years, smoking habit, alcohol consumption, marriage status, and strata status (urban and rural) were determined using a sociodemography questionnaire. Obesity was defined as body mass index $(\mathrm{BMI}) \geq 30 \mathrm{~kg} / \mathrm{m}^{2}$. The presence of chronic diseases (hypertension, diabetes, hypercholesterolemia, arthritis, stroke, cardiovascular disease, chronic obstructive lung disorder, and cancer) was determined using a self-reported medical history questionnaire. Participants were classified as having depressive

Table 1 Criteria of MCR syndrome

\begin{tabular}{ll}
\hline & Criteria of MCR syndrome \\
\hline 1. & Absence of dementia \\
3. & Subjective memory complaints \\
4 & Slow gait \\
\hline
\end{tabular}


symptoms if they scored five and above on a 15 -items Geriatric Depressive Scale (GDS).

\section{Statistical analysis}

All data were analysed using IBM Statistical Package for Social Science (SPSS) version 22 (IBM Corp., Chicago, IL). Significant value was set at $p<0.05$. Comparison of characteristics between MCR and non-MCR groups were analysed using chi-squared $\left(\chi^{2}\right)$ tests for categorical variables and independent $t$-test for continuous variables. Hierarchical binary logistic regression was employed to determine the risk factors of MCR syndrome, adjusted for age, gender and educational years. Results were reported as adjusted odd ratio and 95\% confidence interval (CI).

\section{Results}

Prevalence of MCR syndrome

A total of $3.4 \%$ of the subjects fulfilled the criteria for MCR syndrome. Women had a higher prevalence of MCR syndrome $(74.5 \%)$ compared to men $(25.5 \%)(p=0.001)$. As shown in Table 2, respondents with MCR syndrome were significantly older and had lower educational years than those without MCR syndrome $(p<0.001)$. Majority of them were also living in rural area $(p=0.011)$, unmarried, divorced, widow or widower $(p=0.002)$.

\section{Risk factors of MCR syndrome}

Table 3 shows the findings of hierarchical binary logistic regression analysis, adjusted for age, gender and education years. Increasing age (Adjusted OR: 1.13, 95\% CI: 1.074-1.197, $p<0.001$ ), being female (Adjusted OR: 3.67, 95\% CI: 1.485-9.070, $p=0.005)$ and living in rural area (Adjusted OR: 2.19, 95\% CI: 1.098-4.348, $p=0.026$ ) increased risk of having MCR syndrome. Other factors associated with increased risk of MCR syndrome were obesity (OR: 3.82, 95\% CI: 1.699-8.570, $p=0.001$ ), diabetes (Adjusted OR: 2.04, 95\% CI: 1.013-4.109, $p=0.046$ ), cardiovascular disease (Adjusted OR: 2.50, 95\% CI: 1.0046.203, $p=0.049$ ), and cancer (Adjusted OR: 6.57, 95\% CI: $1.177-36.650, p=0.032$ ).

\section{Discussion}

This study showed that the prevalence of MCR syndrome among low- income community dwelling older adults in an Asian country (Malaysia) was $3.4 \%$. This figure is lower than findings from studies conducted in other Asian countries. A meta-analysis showed that the MCR syndrome prevalence among adults from Korea, China, Japan (Kurihara Project) and India (Kerala-Einstein Study), ranged from 10 to 15\% [12]. The differences could be due to several factors including age range, sample size and target group [12, 13]. For instance, the highest MCR syndrome prevalence (15\%) was reported in an Indian cohort, which enrolled participants with memory complaints only. In addition, the age range of subjects from the present study was 60 to 92 years old, different from that reported in Japan (74 to 95 years old) and Korea (65 to 102 years old). Sample sizes of cohorts in India $(n=271)$, Japan $(n=514)$ and Korea $(n=549)$ were also smaller as compared to the present study [12].

Demographic characteristics of the elderly varied in rural and urban settings in terms of loneliness, lack of financial stability, and emotional strain [18]. Single elderly with poor general health status living in the rural areas were at higher risk of depression [19]. According to Koris et al. [20], majority of the elderly from low- income groups experience castatrophic health expenditure (CHE), with the total direct expenses exceeding $10 \%$ of household income. Malaysian elderly in rural areas expressed greater need for health services and experienced more financial hardship than those in urban areas [21]. They still have to be formally employed to maintain their livelihood [19]. Complex neuropsychological testing or neuroimaging services are often limited in rural areas. Therefore, determination of MCR syndrome can be used to predict the risk of developing cognitive impairment and dementia, especially for elderly in rural areas and belonging to the low-income category.

Previous studies showed no significant gender disparities in MCR prevalence [12, 13]. However, in the present study, women had a significantly higher prevalence of MCR compared to men. A study conducted among Malaysian older adults found that women had significantly higher prevalence of frailty $(11.8 \%)$ than men $(5.2 \%)(p<0.001)$ [22]. This could be due to the fact that women have lower muscle mass [23] and lose their lean body mass faster than men during the aging process [24] putting them at a higher risk of becoming physically frail.

Similar to the previous studies, participants with MCR were older, less educated, had obesity and diabetes [11, 13]. A meta-analysis on MCR demonstrated that MCR syndrome is significantly associated with cardiovascular disease and its risk factors such as hypertension, diabetes, stroke and obesity [25]. These findings suggest that a vascular mechanism may underlie the pathophysiology of MCR syndrome. Cardiovascular risk factors increased the risk of cerebral ischemia affecting the periventricular white matter [26, 27]. Brain white matter plays an important role in executive function and cognitive processing, as well as control of gait $[26,28]$. The effects of diabetes on cognitive decline may relate to macrovascular and microvascular complications. Macrovascular complications such as hyperglycaemia, hyperlidipedimia, hypertension and inflammation may lead to brain structural changes and loss of brain volume [29, 
Table 2 Comparison of baseline characteristics

\begin{tabular}{|c|c|c|c|}
\hline \multirow[t]{2}{*}{ Variables } & \multirow{2}{*}{$\begin{array}{l}\text { MCR }(n=47) \\
n(\%) / \text { Mean } \pm S D\end{array}$} & \multirow{2}{*}{$\begin{array}{l}\text { NON-MCR }(n=1319) \\
n(\%) / \text { Mean } \pm \text { SD }\end{array}$} & \multirow[t]{2}{*}{$p$ value } \\
\hline & & & \\
\hline Age (years) ${ }^{a}$ & $72.74 \pm 7.08$ & $68.52 \pm 5.88$ & $<0.001^{*}$ \\
\hline \multicolumn{4}{|l|}{ Gender $^{\mathrm{b}}$} \\
\hline Male & $12(25.5)$ & $660(50.0)$ & \multirow[t]{2}{*}{$0.001^{*}$} \\
\hline Female & $35(74.5)$ & $659(50.0)$ & \\
\hline Education (years) ${ }^{a}$ & $3.26 \pm 2.91$ & $5.04 \pm 3.81$ & $<0.001^{*}$ \\
\hline \multicolumn{3}{|l|}{ Marrital status ${ }^{b}$} & \multirow[t]{3}{*}{0.002} \\
\hline Married & $21(44.7)$ & $888(67.3)$ & \\
\hline Single/widow/widower/divorced & $26(55.3)$ & $431(32.7)$ & \\
\hline \multicolumn{4}{|l|}{ Smoking Habit ${ }^{\text {b }}$} \\
\hline Smoker & $7(14.9)$ & $239(18.1)$ & \multirow[t]{2}{*}{0.235} \\
\hline Non Smoker & $40(72.1)$ & $1080(81.9)$ & \\
\hline \multicolumn{4}{|l|}{ Alcohol Consumption ${ }^{\mathrm{b}}$} \\
\hline Yes & $0(0)$ & $58(4.4)$ & \multirow[t]{2}{*}{0.260} \\
\hline No & $47(3.6)$ & $1261(95.6)$ & \\
\hline \multicolumn{3}{|l|}{ Strata Status ${ }^{b}$} & \multirow[t]{3}{*}{$0.011^{*}$} \\
\hline Rural & $34(72.3)$ & $699(53.0)$ & \\
\hline Urban & $13(27.7)$ & $620(47.0)$ & \\
\hline \multicolumn{3}{|l|}{ Obesity $^{b}$} & \multirow[t]{3}{*}{0.039} \\
\hline Yes & $11(23.4)$ & $160(12.1)$ & \\
\hline No & $36(76.6)$ & $1159(87.9)$ & \\
\hline $\mathrm{GDS}^{\mathrm{a}}$ & $3.64 \pm 2.88$ & $3.03 \pm 2.33$ & 0.160 \\
\hline \multicolumn{4}{|l|}{ Chronic diseases $^{b}$} \\
\hline \multicolumn{4}{|l|}{ Hypertension } \\
\hline Yes & $27(57.4)$ & $675(51.6)$ & \multirow[t]{2}{*}{0.461} \\
\hline No & $20(42.6)$ & $633(48.4)$ & \\
\hline \multicolumn{4}{|l|}{ Diabetes } \\
\hline Yes & $17(36.2)$ & $342(26.1)$ & \multirow[t]{2}{*}{0.132} \\
\hline No & $30(63.8)$ & $966(73.9)$ & \\
\hline \multicolumn{4}{|l|}{ Hypercholesterolemia } \\
\hline Yes & $20(42.6)$ & $530(40.5)$ & \multirow[t]{2}{*}{0.765} \\
\hline No & $27(57.4)$ & $778(59.5)$ & \\
\hline \multicolumn{4}{|l|}{ Arthritis } \\
\hline Yes & $12(25.5)$ & $331(25.3)$ & \multirow[t]{2}{*}{1.000} \\
\hline No & $35(74.5)$ & $977(74.7)$ & \\
\hline Stroke & & & \\
\hline Yes & $0(0)$ & $20(1.5)$ & 0.393 \\
\hline No & $47(100)$ & $1288(98.5)$ & \\
\hline Cardiovascular disease & & & \\
\hline Yes & $8(17.0)$ & $116(8.9)$ & 0.068 \\
\hline No & $39(83.0)$ & $1192(91.1)$ & \\
\hline Chronic obstructive lung disease & & & \\
\hline Yes & $1(0.4)$ & $4(0.3)$ & 0.816 \\
\hline No & 228 (99.6) & $1183(99.7)$ & \\
\hline
\end{tabular}


Table 2 Comparison of baseline characteristics (Continued)

\begin{tabular}{lll}
\hline Variables & MCR $(n=47)$ & NON-MCR $(n=1319) \quad p$ value \\
& $n(\%) /$ Mean \pm SD & \\
\hline Cancer & & $10(0.8)$ \\
Yes & $2(4.3)$ & $1287(99.2)$ \\
No & $45(95.7)$ & 0.063 \\
\hline
\end{tabular}

GDS Geriatric Depressive Scale

Independent t-test

${ }^{\mathrm{b}} \mathrm{Chi}$-squared test

*Significant at $p<0.05$

30]. Additionally, microvascular change such as diabetic retinopathy was also associated with lower verbal fluency, mental flexibility and processing speed [31]. Previous studies that have examined the association between arthritis and cognition suggested that arthritis might increase the risk for cognitive impairment [32-34]. Arthritis and cognitive impairment are both associated with factors such as fatigue, pain, depression and increased risk of physical inactivity. However, arthritis was not significantly associated with risk of MCR in the present study.

Previous studies also reported that participants with MCR were more depressed compared to non-MCR group [11, 13]. Our colleagues from the same large-scale population study showed that functional status is one of

Table 3 Factors that significantly associated with MCR syndrome

\begin{tabular}{|c|c|c|c|c|}
\hline \multirow{2}{*}{$\begin{array}{l}\text { Independent } \\
\text { variables }\end{array}$} & \multirow{2}{*}{$\begin{array}{l}\text { Adjusted } \\
\text { OR }\end{array}$} & \multicolumn{2}{|l|}{$95 \% \mathrm{Cl}$} & \multirow[t]{2}{*}{$p$ value } \\
\hline & & Lower & Upper & \\
\hline$\overline{\text { Age }}$ & 1.13 & 1.074 & 1.197 & $<0.001$ \\
\hline \multicolumn{5}{|l|}{ Gender } \\
\hline \multicolumn{5}{|l|}{ Male } \\
\hline Female & 3.67 & 1.485 & 9.070 & 0.005 \\
\hline \multicolumn{5}{|l|}{ Strata Status } \\
\hline \multicolumn{5}{|l|}{ Urban } \\
\hline Rural & 2.19 & 1.098 & 4.348 & 0.026 \\
\hline \multicolumn{5}{|l|}{ Obesity } \\
\hline \multicolumn{5}{|l|}{ No } \\
\hline Yes & 3.82 & 1.699 & 8.570 & 0.001 \\
\hline \multicolumn{5}{|l|}{ Diabetes } \\
\hline \multicolumn{5}{|l|}{ No } \\
\hline Yes & 2.04 & 1.013 & 4.109 & 0.046 \\
\hline \multicolumn{5}{|c|}{ Cardiovascular disease } \\
\hline No & 2.50 & 1.004 & 6.203 & 0.049 \\
\hline \multicolumn{5}{|l|}{ Yes } \\
\hline \multicolumn{5}{|l|}{ Cancer } \\
\hline \multicolumn{5}{|l|}{ No } \\
\hline Yes & 6.57 & 1.177 & 36.650 & 0.032 \\
\hline
\end{tabular}

the predictors that significantly associated with geriatric depressive disorders among Malaysian older adults [35]. Depressive symptoms were also reported highest in Mild Cognitive Impairment (MCI) group [36]. Nevertheless, depressive symptom was not associated with the risk of MCR in the present study. Both MCR and non-MCR groups reported not having any depressive symptom as measured using GDS. This might explain the lack of association of depressive syndrome with MCR.

The strength of this study is that it is one of very few studies investigating MCR among low-income populations in Asia. The limitation of the present study is that the true causal relationships could not be derived as this was a cross sectional study. Nevertheless, the multiple factors associated with MCR syndrome in the present study were in agreement with the risk factors of cognitive impairment and dementia [37]. Future validation studies are needed so that this simple clinical approach can be used to improve dementia risk assessments, develop interventions and preventive measures to optimize cognitive performance of Malaysian elderly.

In conclusion, Malaysian older adults from the low-income (B40) group, especially women living in rural areas, with obesity, diabetes, heart disease and cancer were at a higher risk of MCR syndrome. The cost effective MCR concept can be easily applied in various settings, particularly in rural areas that lack of healthcare facilities, to identify high-risk individuals. Further investigation on MCR as a predementia syndrome will help in development of preventive strategies and interventions to reduce the growing burden of dementia, especially among individuals with low socioeconomic status.

\section{Abbreviations}

ADL: Activities of Daily Living; B40: Bottom 40\%; BMI: Body Mass Index; CHE: Castatrophic Eealth expenditure; Cl: Confidence Interval; GDS: Gereiatric Depression Scale; MCI: Mild Cognitive Impairment; MCR: Motoric Cognitive Risk; MMSE: Mini Mental State of Examination; OR: Odd Ratio; SD: Standard Deviation; SPSS: Statistical Package for Social Sciences; TUA: Towards Useful Aging; $x^{2}$ : Chi-square

\section{Acknowledgments}

We acknowledge the contributions of the LRGS TUA study group including the co-researchers, research assistants, enumerators, phlebotomies, research and science officers. We thank the participants, their family 
members, community leaders and the local authorities for their cooperation throughout recruitment and data collection processes.

\section{Funding}

This study was funded by Ministry of Higher Education Malaysia under the Longterm Research Grant Scheme (LRGS) LRGS/BU/2012/UKM-UKM/K/01. The funders had no role in study design, data collection and analysis, decision to publish, or preparation of the manuscript. The authors also acknowledged the financial assistance for publication received from the Research University Grant awarded by the Ministry of Health to the National University of Malaysia specifically for the Consortium of B40 Research (CB40R) under the auspice of B40 Grand Challenges (IDE 2018-01).

\section{Availability of data and materials}

All relevant data can be found within the paper.

\section{About this supplement}

This article has been published as part of BMC Public Health Volume 19 Supplement 4, 2019: Health and Nutritional Issues Among Low Income Population in Malaysia. The full contents of the supplement are available online at https://bmcpublichealth.biomedcentral.com/articles/supplements/ volume-19-supplement-4.

\section{Authors' contributions}

HL was responsible for responsible for conceptualisation, acquisition of data, analysis of data, initial and final draft. AFML and SS were responsible for conceptualisation, initial draft and revising draft for content. MB was responsible for acquisition of data and analysis of data. BCC was responsible for conceptualisation and revising draft for content. All the authors have read and approved the final manuscript.

\section{Ethical approval and consent to participate}

This study was approved by Medical Research and Ethics Committee of the Universiti Kebangsaan Malaysia (UKM). Informed consent was also obtained from all participants prior the data collection.

\section{Consent for publication}

Not applicable.

\section{Competing interests}

The authors report no conflict of interest related to the work.

\section{Publisher's Note}

Springer Nature remains neutral with regard to jurisdictional claims in published maps and institutional affiliations.

\section{Author details}

${ }^{1}$ Centre for Healthy Aging and Wellness, Faculty of Health Sciences, Universiti Kebangsaan Malaysia, Jalan Raja Muda Abdul Aziz, 50300 Kuala Lumpur, Malaysia. ${ }^{2}$ Department of Applied Chemistry and Applied Biology, College of Applied Sciences, Palestine Polytechnic University, HebronWest BankPalestine. ${ }^{3}$ Ohio Musculoskeletal and Neurological Institute (OMNI) and Department of Biomedical Sciences, Ohio University, Athens, OH, USA. ${ }^{4}$ Program of Biomedical Science, Faculty of Health Sciences, UKM KL Jalan Raja Muda Abd Aziz, Kuala Lumpur 50300, Malaysia.

\section{Published: 13 June 2019}

\section{References}

1. Olivia TSL, Khan S, Vergara RG, Khan N. Policies and protections for ageing society in Malaysia. Journal of Southeast Asian Research. 2016. https://doi. org/10.5171/2016.974366.

2. Alavi K, Sail RM, Mohamad MS, Omar M, Subhi N, Chong ST, et al. Exploring the meaning of ageing and quality of life for tge sub-urban older people. Pertanika J. Soc. Sci. \& Hum. 2011; 19(S): 41-8. Available from: https://core. ac.uk/download/pdf/153820349.pdf. Accessed 25 Apr 2019.

3. Selvaratnam DP, Abu Bakar N, Haji Idris NA. The health determinants of elderly Malaysiam population. Prosiding Perkem VII 2012; 2: 1195-1199. Available from: https://docplayer.net/32134290-Kesejahteraan-ekonomiwarga-emas-di-malaysia-perbezaan-gender-economic-well-being-of-elderlyin-malaysia-gender-difference.html. Accessed 25 Apr 2019.
4. Singh DKA, Ibrahim A, Chong PK, Subramaniam P. Attitude towards ageing and physical performance among adults 55 years old and above. Malaysian Journal of Public Health Medicine 2018; 1: 10-17. Available from: https://www. mjphm.org.my/mjphm/journals/2018\%20-\%20Special\%20Volume\%20(1)/ATTIT UDE\%20TOWARDS\%20AGEING\%20AND\%20PHYSICAL\%20PERFORMANCE\%20 AMONG\%20ADULTS\%2055\%20YEARS\%200LD\%20AND\%20ABOVE. Accessed 25 Apr 2019

5. Abu Bakar N, Haji Idris NA, Selvaratnam DP. Economic well-being of elderly in Malaysia: gender difference. Prosiding Perkem IV. 2009;1:316-23.

6. Dobkin $\mathrm{BH}$. Short-distance walking speed and timed walking distance: redundant measures for clinical trials? Neurology. 2006;66(4):584-6. https:// doi.org/10.1212/01.wnl.0000198502.88147.dd.

7. Buracchio T, Dodge HH, Howieson D, Wasserman D, Kaye J. The trajectory of gait speed preceding mild cognitive impairment. Arch Neurol. 2010;67(8): 980-6. https://doi.org/10.1001/archneurol.2010.159.

8. Mielke MM, Roberts RO, Savica R, Cha R, Drubach DI, Christianson T, et al. Assessing the temporal relationship between cognition and gait: slow gait predicts cognitive decline in the Mayo Clinic study of aging. J Gerontol A Biol Sci. 2013;68(8):929-37. https://doi.org/10.1093/gerona/gls256.

9. Verghese J, Lipton RB, Hall CB, Kuslansky G, Katz MJ, Buschke H. Abnormality of gait as a predictor of non-Alzheimer's dementia. N Engl J Med. 2002; 347(22):1761-8

10. Verghese J, Wang C, Lipton RB, Holtzer R, Xue X. Quantitative gait dysfunction and risk of cognitive decline and dementia. J Neurol Neurosurg Pyschiatry. 2007;78(9):929-35. https://doi.org/10.1136/jnnp.2006.106914.

11. Verghese J, Wang C, Lipton RB, Holtzer R. Motoric cognitive risk syndrome and the risk of dementia. J Gerontol A Biol Sci. 2013;68(4):412-8. https://doi. org/10.1093/gerona/gls191.

12. Verghese J, Annweiler C, Ayers E, Barzilai N, Beauchet O, Bennett DA, et al. Motoric cognitive risk syndrome: multicountry prevalence and dementia risk. Neurology. 2014;83(8):718-26. https://doi.org/10.1212/WNL. 0000000000000717

13. Doi T, Verghese J, Shimada H, Makizako H, Tsutsumimoto K, Hotta R, et al. Motoric cognitive risk syndrome: prevalence and risk factors in Japanese seniors. J Am Med Dir Assoc. 2015;16(12):1103e21-5. https://doi.org/10. 1016/j.jamda.2015.09.003.

14. Department of Statistics Malaysia. Report of household income and basic amenities survey 2016. [Press release] (9 October 2017). https://www.dosm. gov.my/v1/index.php? $r=$ column/pdfPrev\&id= RUZ5REwveU1ra1hGL21JWVIPRmU2Zz09. Accessed 25 Apr 2019.

15. Shahar S, Omar A, Vanoh D, Hamid TA, Mukari SZM-S, Din NC, et al. Approaches in methodology for population-based longitudinal study on neuroprotective model for healthy longevity (TUA) among Malaysian older adults. Aging Clin Exp Res. 2016;28(6):1089-104. https://doi.org/10.1007/s40520-015-0511-4.

16. Petersen RC. Clinical practice. Mild cognitive impairment. N Engl J Med. 2011;364(23):2227-34. https://doi.org/10.1056/NEJMcp0910237.

17. Katz S, Ford AB, Moskowitz RW, Jackson BA, Jaffee MW. Studies of illness in the aged: the index of ADL: a standardized measure of biological and psychosocial function. JAMA. 1963;185:914-9.

18. Selvaratnam D, Poo BT. Lifestyle of the elderly in rural and urban Malaysia. Ann N Y Acad Sci. 2007;1114:317-25. https://doi.org/10.1196/annals.1396.025.

19. Manaf MRA, Mustafa M, Abdul Rahman MR, Yusof KH, Abd Aziz NA. Factors influencing the prevalence of mental health problems among Malay elderly residing in a rural community: a cross-sectional study. PLoS One. 2016. https://doi.org/10.1371/journal.pone.0156937.

20. Koris R, Nor NM, Haron SA, Ismail NW, Junid SMAS, Nur AM, et al. Sociodemographic, cognitive status and comorbidity determinants of catastrophic health expenditure among elderly in Malaysia. Int J Econs \& Mgmt 2017; 11 (S3):673-690. http://www.ijem.upm.edu.my/vol11noS3/(7)\% 20IJEM\%20(S3)\%202017\%20R2\%20Socio-demographic,\%20Cognitive\%20Sta tus\%20and\%20Comorbidity\%20Determinants\%20of\%20Catastrophic\%20Hea Ith\%20Expenditure\%20among\%20Elderly\%20in\%20Malaysia.pdf. Accessed 25 Apr 2019.

21. Shahar S, Earland J, Abd Rahman S. Social and health profiles of rural elderly Malays. Singap Med J. 2001;42(5):208-13.

22. Badrasawi M, Shahar S, Kaur Ajit Singh D. Risk factors of frailty among multiethnic Malaysian older adults. Int J Gerontol. 2017;11(3):154-60. https://doi. org/10.1016/j.ijge.2016.07.006.

23. Janssen I, Heymsfield SB, Wang Z, Ross R. Skeletal muscle mass and distribution in 468 men and women aged 18-88 yr. J Appl Physiol (1985). 2000; 89(1): 818. Available from: doi: https://doi.org/10.1152/jappl.2000.89.1.81. 
24. Visser M, Kritchevsky S, Goodpaster B, Newman AB, Nevitt MC, Stamm E, et al. Leg muscle mass and composition in relation to lower extremity performance in men and women aged 70 to 79 : the health, aging and body composition study. J Am Geriatr Soc. 2002;50(5):897-904.

25. Beauchet O, Sekhon H, Barden J, Liu-Ambrose T, Chester VL, Szturm T, et al. Association of motoric cognitive risk syndrome with cardiovascular disease and risk factors: results from an original study and meta-analysis. J Alzheimers Dis. 2018;64(3):875-87. https://doi.org/10.3233/JAD-180203.

26. Santos CY, Snyder PJ, Wu W-C, Zhang M, Echeverria A, Alber J. Pathophysiologic relationship between Alzheimer's disease, cerebrovascular disease, and cardiovascular risk: a review and synthesis. Alzheimers Dement. 2017;7:69-87. https://doi.org/10.1016/j.dadm.2017.01.005.

27. Solfrizzi V, Panza F, Colacicco AM, D'Introno A, Capurso C, Torres F, et al. Vascular risk factors, incidence of $\mathrm{MCl}$, and rates of progression to dementia. Neurology. 2004;63(10):188291. https://doi.org/10.1212/01.WNL.0000144281. 38555.E3.

28. Smith EE, O'Donnell M, Dagenais G, Lear SA, Wielgosz A, Sharma M, et al. Early cerebral small vessel disease and brain volume, cognition, and gait. Ann Neurol. 2015;77(2):251-61. https://doi.org/10.1002/ana.24320

29. Reijmer YD, van den Berg E, Ruis C, Kappelle LJ, Biessels GJ. Cognitive dysfunction in patients with type 2 diabetes. Diabetes Metab Res Rev 2010; 26(7): 507-519. doi: https://doi.org/10.1002/dmrr.1112.

30. Strachan MW, Reynolds RM, Marioni RE, Price JF. Cognitive function, dementia and type 2 diabetes mellitus in the elderly. Nat Rev Endocrinol. 2011;7(2):108-14. https://doi.org/10.1038/nrendo.2010.228.

31. Ding J, Strachan MW, Reynolds RM, Frier BM, Deary IJ, Fowkes FGR, et al. Diabetic retinopathy and cognitive decline in older people with type 2 diabetes: the Edinburgh type 2 diabetes study. Diabetes. 2010;59(11):28839. https://doi.org/10.2337/2Fdb10-0752.

32. Huang SW, Wang WT, Chou LC, Liao CD, Liou TH, Lin HW. Osteoarthritis increases the risk of dementia: a nationwide cohort study in Taiwan. Sci Rep 2015; 5: 10145. Available from: https://www.nature.com/articles/srep10145. Accessed 25 Apr 2019

33. Lu K, Wang HK, Yeh CC, Huang C-Y, Sung P-S, Wang L-C, et al. Association between autoimmune rheumatic diseases and the risk of dementia. Biomed Res Int. 2014;2014:861812. https://doi.org/10.1155/2014/861812.

34. Wallin K, Solomon A, Kareholt I, Tuomilehto J, Soininen H, Kivipelto M. Midlife rheumatoid arthritis increases the risk of cognitive impairment two decades later: a population-based study. J Alzheimers Dis. 2012;31(3):66976. https://doi.org/10.3233/JAD-2012-111736.

35. Vanoh D, Shahar S, Yahya HM, Hamid TA. Prevalence and determinants of depressive disorders among community-dwelling older adults: findings from the towards useful aging study. Int J Gerontol. 2016;10(2):81-5. https:// doi.org/10.1016/j.jjge.2016.02.001.

36. Vanoh D, Shahar S, Din NC, Omar A, Vyrn CA, Razali R, et al. Predictors of poor cognitive status among older Malaysian adults: baseline findings from the LRGS TUA cohort study. Aging Clin Exp Res. 2017;29(2):173-82. https:// doi.org/10.1007/s40520-016-0553-2.

37. Baumgart M, Synder HM, Carrillo MC, Fazio S, Kim H, Johns H. Summary of the evidence on modifiable risk factors for cogntiive decline and dementia: a population-based perspective. Alzheimers Dement. 2015;11(6):718-26. https://doi.org/10.1016/j.jalz.2015.05.016.

Ready to submit your research? Choose BMC and benefit from:

- fast, convenient online submission

- thorough peer review by experienced researchers in your field

- rapid publication on acceptance

- support for research data, including large and complex data types

- gold Open Access which fosters wider collaboration and increased citations

- maximum visibility for your research: over $100 \mathrm{M}$ website views per year

At $\mathrm{BMC}$, research is always in progress.

Learn more biomedcentral.com/submissions 